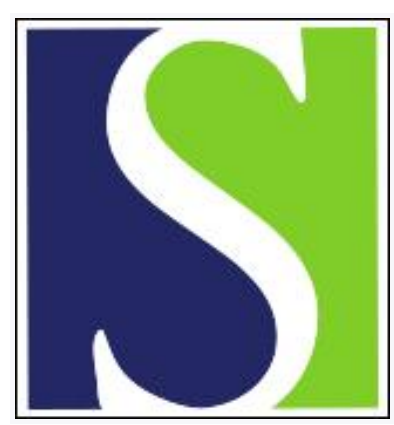

Scand J Work Environ Health 1975;1(4):249-253

https://doi.org/10.5271/sjweh.2841

Issue date: Dec 1975

Effects of a welding helmet and dust respirators on respiration at rest and during exercise.

by White $T$, Schütz $A$, Lundgren $K-M$

Key terms: carbon dioxide; carbon dioxide tension; dust respirator; exercise; experimental physiology; respiration; rest; ventilation; welding helmet

This article in PubMed: www.ncbi.nlm.nih.gov/pubmed/1228904

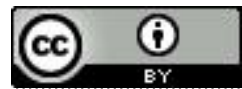




\title{
Effects of a welding helmet and dust respirators on respiration at rest and during exercise
}

\author{
by THOMAS WHITE, M.D.,1 ANDREJS SCHÜTZ, B.Sc.,"² and KARL-MAGNUS \\ LUNDGREN, M.D. ${ }^{3}$
}

\begin{abstract}
WHITE, T., SCHÜTZ, A. and LUNDGREN, K.-M. Effects of a weilding helmet and dust respirators on respiration at rest and during exercise. Scand. $j$. work environ. \& health 1 (1975) $249 \longrightarrow 254$. The influence of welders' protective devices on respiration at rest and during exercise was studied under labonatory conditions. During exercise the devices caused increased ventilation and increased arterial carbon dioxide tension. In the case of the welding helmet the increase was probably a consequence of increased dead space. It is concluded that the physiological affects on respiration are of minor importance in themselves, but they should be taken into account when the degree of exposure to welding fumes is evaluated.
\end{abstract}

Key words: experimental physiology, welding helmet, dust respirator, respiration, ventilation, carbon dioxide tension, exercise.

Electric welding with coated electrodes can cause headache, nausea, and excessive fatigue. These symptoms may be caused by toxic substances in the fumes coming from the welding rods.

It is difficult to estimate the amount of fumes actually inhaled because the breathing pattern, the total pulmonary ventilation, and the access of the fumes to the face is likely to be influenced by factors such as the level of physical effort and the protective devices used. It has been found, however, that the concentration of welding fumes can be two to three times lower inside a welding helmet than outside it (Schültz, unpublished results). The difference in concentration may partly be due to the fact that the air inside the helmet also includes expired air, from

1 Department of Clinical Physiology, University of Lund, Lund, Sweden.

2 Department of Occupational Medicine, University Hospital, Lund, Sweden.

3 Department of Medicine, Óresundsvarvet Shipyard, Landskrona, Sweden.

Reprint requests to: Mr. Andrejs Schütz, Yrkesmedicinska kliniken, Lasarettet, S-221 85 Lund, Sweden. which part of the fumes has been removed by the lungs.

The objective of the present investigation was to determine whether the use of a welding hellmet and a dust respiratior affects respiration.

\section{MATERIAL AND METHODS}

\section{Subjects}

Six male shipyard welders, who were accustomed to the protective devices and who were experienced in electric welding, volunteered to take part in the study after the nature of the procedures was explained to them. They were informed that the experiments were aimed at improving the working conditions of welders in general but that they themselves would not necessarily benefit from the experiments. One subject (no. 1) had had pulmonary tuberculosis about 25 years earlier. All of the subjects were healthy at the time of the investigation, however, and a routine physical examination produced no abnormal findings. 


\section{Equipment}

Three types of protective devices were tested. All suibjects used a skuliguard/ welding helmet combination (Tegma, Malmö, catalog no. 34950) (fig. 1). In addition two types of colloidal dust respirators were tested, either separately or in combination with the helmet. Subjects 1,2 , and 3 used a respirator with a prolonged exhalation valve directed downwards (Bicapa, Stockholm, catalog no. 2622). Subjects 4,5 , and 6 used a respirator consisting of a facepiece connected by means of a breathing tube to a beltattached filter holder (Draeger, Lübeck, catalog no. RM 8740).

The welding helmet was attached to the skullguard with a mechanism which permitted the welder to swing the helmet up on the skullguard when not in use. When swung down in welding position, the helmet fitted close to the brim of the skullguard.

\section{Methods}

In a preliminary examination the results of conventional dynamic spirometry, a resting 12-lead electrocandiogram (ECG), and an exercise test on a bicycle ergometer with ECG recording were normal. During the exercise test the subjects were tested with an initial work load of $50 \mathrm{~W}$ and stepwise increments of $50 \mathrm{~W}$ until exhaustion. Ait each level the subjects were required to attain a steady state, as judged from the heart rate (increase in heart rate not more than four beats per minute between two measuremen's with an interval of $2 \mathrm{~min}$ ), before moving to a higher level. The maximal physical work capacity was defined as the highest level at which the subject achieved a steady state.

An ECG was also recorded while the subject welded. During one ordinary work day a 12-h ECG recording was made on a portable lightweight tape recorder. Heart rate was measured from the ECG.

During the experiment an ECG with chest leads was recorded at 2-min intervals (at rest) or continuously (during exercise).

A teflon catheter was introduced percutaneously into the left brachial artery by the Seldinger technique. Arterial blood samples were obtained anaerobically and analyzed immediately. Arterial tensions
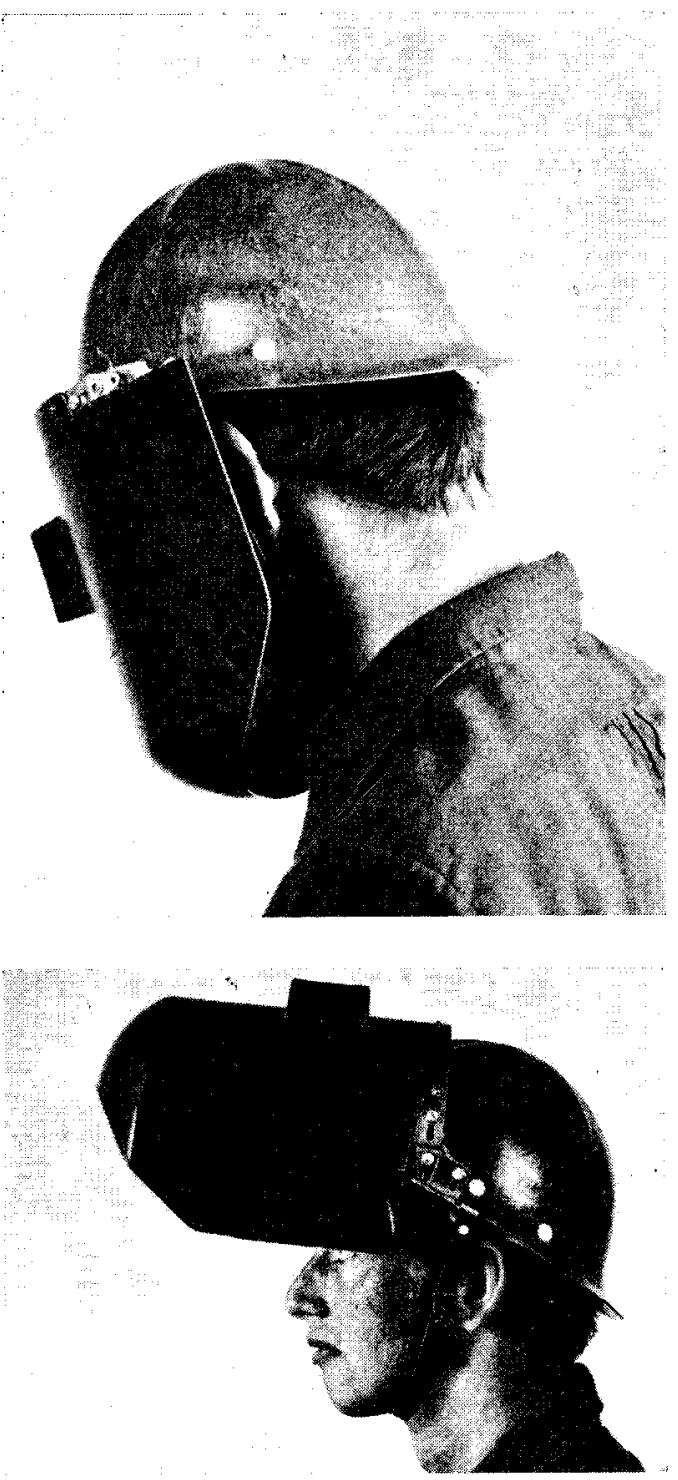

Fig. 1. Skullguard/welding helmet combination. The subject wore the device during the entire experimental procedure. (Photo A. Rosengren)

of oxygen $\left(\mathrm{PaO}_{2}\right)$ and of carbon dixoide $\left(\mathrm{PaCO}_{2}\right)$ were determined directly by conventional blood gas electrodes (Eschweiler, Keil, Germany), and $\mathrm{pH}$ was determined according to Astrup (Radiometer, Copenhagen, Denmark).

The tijdal air of five of the six subjects was measured by a strain-gauge technique. A mercury-filled sillastic tube was attached to the ventral circumference of the chest, and a constant voltage was applied to the 
Table 1. Physiological measurements from six subjects at rest and during exercise. The subjeots wore the skullguard with the welding helmet turned up (fig 1).

\begin{tabular}{|c|c|c|c|c|c|c|c|c|}
\hline $\begin{array}{l}\text { Sub- } \\
\text { ject }\end{array}$ & $\begin{array}{l}\text { Age } \\
\text { (yr) }\end{array}$ & & $\begin{array}{c}\text { Heart } \\
\text { rate } \\
\text { (beats } / \mathrm{min} \text { ) }\end{array}$ & $\begin{array}{l}\text { Respir- } \\
\text { atory } \\
\text { rate } \\
\text { (breaths/ } \\
\text { min) }\end{array}$ & $\begin{array}{l}\text { Venitil- } \\
\text { ation } \\
\text { (l/min) }\end{array}$ & $\begin{array}{c}\mathrm{P}_{\mathrm{a}} \mathrm{CO}_{2} \\
(\mathrm{~mm} \mathrm{Hg})\end{array}$ & $\begin{array}{c}\mathrm{P}_{2} \mathrm{O}_{2} \\
(\mathrm{~mm} \mathrm{Hg})\end{array}$ & $\mathrm{pH}$ \\
\hline 1 & 51 & $\left\{\begin{array}{l}\text { Rest } \\
75 \text { W }\end{array}\right.$ & $\begin{array}{r}84-87 \\
131-148\end{array}$ & $24-28$ & - & $\begin{array}{l}38.5-39.5 \\
38.5-39.0\end{array}$ & $\begin{array}{l}76-80 \\
80-84\end{array}$ & $\begin{array}{c}7.40-7.42 \\
7.38\end{array}$ \\
\hline 2 & 37 & $\left\{\begin{array}{l}\text { Rest } \\
\text { 35 W }\end{array}\right.$ & $\begin{array}{r}73-79 \\
130-144\end{array}$ & $\begin{array}{l}20-23 \\
28-31\end{array}$ & $\begin{array}{r}7-8 \\
13-16\end{array}$ & $\begin{array}{l}39.5-41.0 \\
38.5-42.5\end{array}$ & $\begin{array}{l}70-77 \\
75-81\end{array}$ & $\begin{array}{l}7.42-7.43 \\
7.38-7.42\end{array}$ \\
\hline 3 & 37 & $\left\{\begin{array}{l}\text { Rest } \\
75 \mathrm{~W}\end{array}\right.$ & $\begin{array}{r}65-72 \\
116-132\end{array}$ & $\begin{array}{l}13-14 \\
21-24\end{array}$ & $\begin{array}{l}13-16 \\
30\end{array}$ & $\begin{array}{l}38.0-39.0 \\
36.5-37.5\end{array}$ & $\begin{array}{l}80-91 \\
89-92\end{array}$ & $\begin{array}{l}7.42-7.43 \\
7.39-7.42\end{array}$ \\
\hline 4 & 39 & $\left\{\begin{array}{l}\text { Rest } \\
100 \mathrm{~W}\end{array}\right.$ & $\begin{array}{r}48-54 \\
100-120\end{array}$ & $\begin{array}{r}9-13 \\
17-20\end{array}$ & $\begin{array}{r}9-10 \\
57-69\end{array}$ & $\begin{array}{l}39.0-40.5 \\
37.0-41.5\end{array}$ & $\begin{array}{l}99-100 \\
92-95\end{array}$ & $\begin{array}{c}7.38 \\
7.35-7.41\end{array}$ \\
\hline 5 & 38 & $\left\{\begin{array}{l}\text { Rest } \\
60 \text { W }\end{array}\right.$ & $\begin{array}{r}79-88 \\
116-120\end{array}$ & $\begin{array}{l}14-16 \\
18-21\end{array}$ & $\begin{array}{r}8-11 \\
52-71\end{array}$ & $\begin{array}{l}36.0-36.5 \\
33.0-36.5\end{array}$ & $\begin{array}{l}88-92 \\
85-92\end{array}$ & $\begin{array}{l}7.40-7.41 \\
7.41-7.45\end{array}$ \\
\hline 6 & 33 & $\left\{\begin{array}{l}\text { Rest } \\
70 \mathrm{~W}\end{array}\right.$ & $\begin{array}{r}81-87 \\
120-129\end{array}$ & $\begin{array}{l}13-15 \\
19-22\end{array}$ & $\begin{array}{r}5-8 \\
33-48\end{array}$ & $\begin{array}{l}38.0-38.5 \\
35.5-40.0\end{array}$ & $\begin{array}{l}85-87 \\
83-89\end{array}$ & $\begin{array}{c}7.41 \\
7.38-7.42\end{array}$ \\
\hline
\end{tabular}

mercury column. By means of a modified Wheatstone bridge arrangement, an electric signal proportional to the stretching of the tube was recorded on an ink-writer. The respiratory chest movements thus recorded were calibrated in terms of breathing volumes by letting the subject breathe into a spirometer with the silastic tube in position on the chest. The measurement was carried out immediately after the test period while the subject was still sitting on the bicycle ergometer.

\section{Experimental design}

Measurements were first made at rest while the subject sat comfortably in a reclining chair. Exercise was then performed on a bicycle ergometer (SiemensElema AB, Stockholm, Sweden). The work load (table 1) was about one-third or onehalf of the subject's maximal physical work capacity and was similar to that measured during welding in the shipyard.

In order to obtain steady-state conditions, we allowed at least $6 \mathrm{~min}$ to pass before making measurements at rest, and at least $8 \mathrm{~min}$ passed before measurements were made during work. As the collection of blood samples, the ECG recording, and the ventilation measurement took a

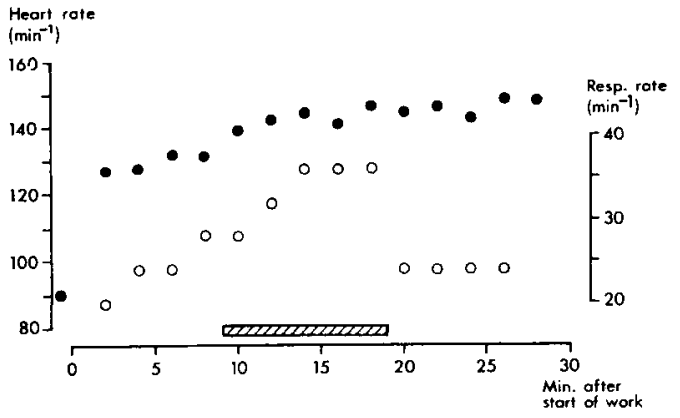

Fig. 2. Subject no. 1; work load 75 W. The hatched bar represents the time when the helmet was in front of the face. Filled circles represent heart rate; and open circles, respiration rate.

certain period of time, usually less than $2 \mathrm{~min}$, and they were begun after $6-8$ min, the duration of each control or experimental period was 6-8 min (at rest) and 8-10 min (during exercise). Before and after each period of breathing with a protective device there was a control period. Thus the protocol for the continuous bicycle ergometer exercise, when only the helmet was being tested (subjects 2 and 3), was 8-10 min without a protective device, $8-10$ minutes with the skullguard/helmet combination, and 8-10 $\mathrm{min}$ again without a protective device, the 
complete test lasting approximately 30 min. When the welding helmet and dust respirator were tested separately and combined (subjects 4,5 , and 6 ), exercise lasted approximately $70 \mathrm{~min}$. Perfect steadystate conditions, as judged from the heart rate, were not achieved, since the heart rate tended to be somewhat higher towards the end of the exercise period than after the initial $8 \mathrm{~min}$ of work (fig. 2).

The room temperature was approximately $20^{\circ} \mathrm{C}$.

\section{RESULTS}

It can be seen in fig. 3 that, at rest, the combined use of a dust respirator and a welding helmet mounted on a skullguard caused an increased $\mathrm{PaCO}_{2}$ in two of the subjects (no. 1 and 2), and an increased pulmonary ventilation in two (no. 2 and 3 ). The dust respirator alone increased the ventilation of subjects 4,5 , and 6 .

More conspicious effects were produced during exercise (fig. 4). With only two

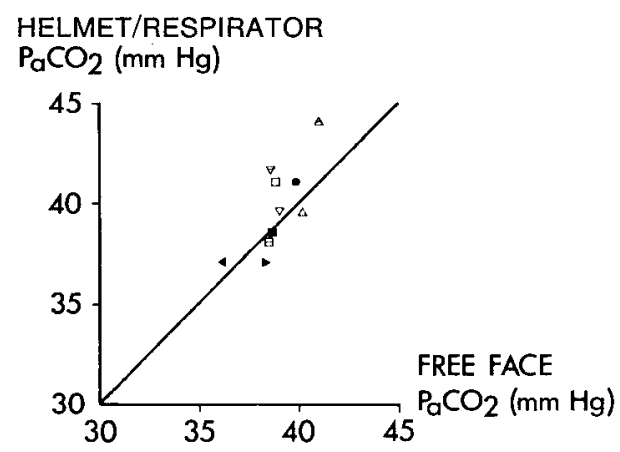

\section{HELMET/RESPIRATOR}

$\dot{\mathrm{V}}_{\mathrm{E}}$ (liters/min)

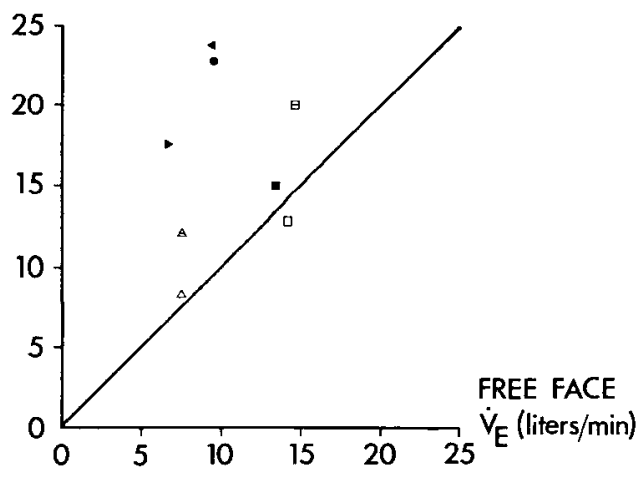

exceptions the welding helmet and dust respirator increased both pulmonary ventilation and $\mathrm{PaCO}_{2}$.

When the subjects were questioned, they stated that breathing during exercise was "heavier" with than without the protective devices. The face also became warm behind the helmet. Otherwise there were no complaints.

\section{DISCUSSION AND CONCLUSIONS}

Increased external respiratory resistance during exercise is known to influence respiration $(4,6)$. It may also increase alveolar carbon dioxide tension $(4,6)$. The results of our experiment with dust respirators could be proof of this increase. However, the welding helmet used in our experiment produced similar effects despite free access to the ambient air and presumably negligible resistance. It should be noted that in the experiments there were no respiratory valves or mouthpieces and the protective devices were worn just as they would be worn during welding work in a shipyard.

The increase in ventilation and in arterial carbon dioxide tension that occurred when the helmet was worn is most readily explained by the possibility that the helmet acted to produce an increased "dead space." The effect appeared to be small or absent at rest, but obvious during exercise at a work load similar to that attained during actual welding work. It is unlikely that "psychogenic" hyperventilation occurred during the experiments since it would have produced a lowered $\mathrm{PaCO}_{2}$, and a lowered $\mathrm{PaCO}_{2}$ rarely occurred. Another possible explanation

Fig. 3. Arterial carbon dioxide itension ( $\left.\mathrm{PaCO}_{2}\right)$ and pulmonary ventilation ( $\left.\hat{V}_{E}\right)$ at rest; breathing with free face (helmet turned up) and breathing with the welding helmet or dust respirator. Control values with free face are means of periods immediately before and immediately after the period with the helmet or respinator. Subjects $1,2,3,4,5$, and 6 are represented by symbols $\nabla, \triangle, \square, O,<$, and $D$, respectively. Open symbols denote the use of the helmet; filled symbols denote the use of the respirator; symbols containing the horizontal bar denote the simultaneous use of the helmet and respirator. The line of identity is shown. 
HEL_MET/RESPIRATOR

$\mathrm{P}_{\mathrm{a}} \mathrm{CO}_{2}(\mathrm{~mm} \mathrm{Hg})$

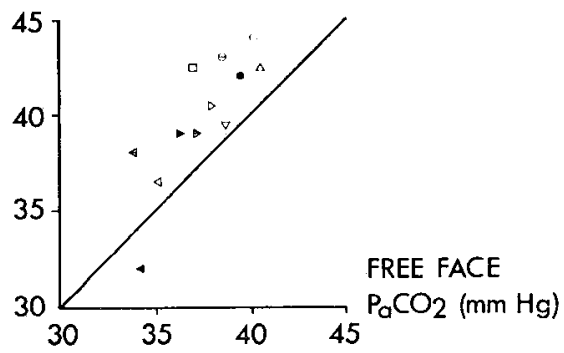

HELMET/RESPIRATOR

$\dot{V}_{E}$ (liters/min)

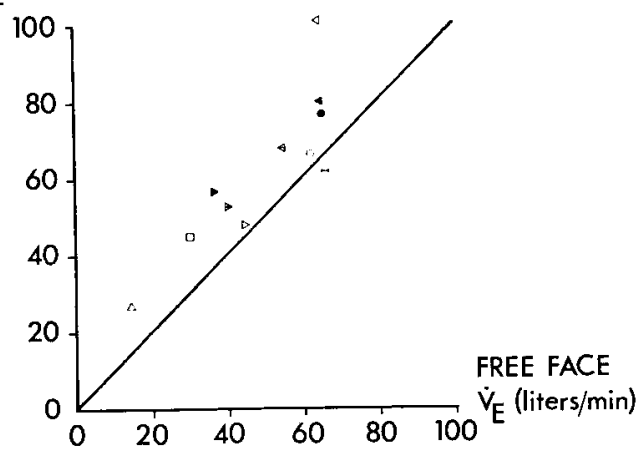

Fig. 4. Anterial carbon dioxide tension ( $\mathrm{PaCO}_{2}$ ) and pulmonary ventilation ( $\dot{V}_{E}$ ) during exercise; breathing with free face (helmet turned up) and breathing with the welding helmet or dust respinator. Control values with free face are means of periods immediately before and immediately after the period with the helmet or respirator. Subjects $1,2,3,4,5$, and 6 are represented by isymbols $\nabla, \triangle, \square, 0, \triangleleft$, and $\triangleright$, respectively. Open symbols denote the use of the helmet; filled symbols denote the use of the respirator; symbols containing the horizontal bar denote the simultaneous use of the helmet and respirator. The line of identity is shown.

for the increased $\mathrm{PaCO}_{2}$ could be that there was an increase in carbon dioxide production, which was not measured in the present experiments. However, we think it is reasonable to assume that the oxygen consumption and the carbon dioxide production did not change significantly because the external work on the bicycle ergometer was constant. Progressive ventilatory changes during the work period were excluded by the observations made during the control periods (fig. 2).

We do not believe that an increased ventilation and/or a moderate increase in
$\mathrm{PaCO}_{2}$ represents a "health hazard" in the conventional sense, but either may contribute to fa'tigue or to other unpleasant experiences which occur during and immediately after work. In our opinion a less spacious helmet would produce less "dead space," and thus pulmonary ventilation and $\mathrm{PaCO}_{2}$ would increase less.

During welding, toxic substances may be absorbed from inhaled fumes, which can, as indicated in several reports $(2,3,5)$, also have local effects, e.g., bronchitis. The increased pulmonary ventilation produced by the welding shield probably means that an increased amount of the fumes is absorbed. Therefore the concentration of toxic substances in the breathing zone is an insufficient measure of the degree of exposure. Further investigations are needed to clarify the situation. However, it is quite evident that measurements made with the subject at rest do not always permit conclusions about events occurring during actual work (1).

\section{REFERENCES}

1. ÅSTRAND, I., EHRNER-SAMUEL, H., KILBOM, $\AA$. and OVRUM, P. Toluene exposure: Concentration in alveolar air and blood at rest and during exposure. Work.environ.-health 9 (1972) $1119-130$.

2. AHLMARK, A. and LONNBERG, B. En hälsoundersökning av 110 elektrosvetsare med långvarig arbetsanamnes [Health examination of 110 electric welders with a history of long-term exposure]. Nord. hyg. tidskr. 11-12 (1953) 238-249.

3. AXELSON, O. "Svetsarbronkit" - epidemiologi i företagshälsovården ["Welders' bronchitis" - Epidemiology in occupational health service]. Läkartidningen 71 (1974) $479-482$.

4. DEMEDTS, M. and ANTHONISEN, N. R. Effects of increased external airway resistance during steady state exercise. $J$. appl. physiol. 35 (1973) 361-366.

5. FOGH, A., FROST, J. and GEORG, J. Respiratory symptoms and pulmonary function in welders. Ann. occup. hyg. 12 (1969) $213-218$.

6. STRINDBERG, L., JOHANSSON, L., CAIRLSSON, A., LJUNGQVIST, E. and ASTRAND, I. Fysiologisk belastning vid ökat landningsmotstånd orsakat av andningsskyydd med filter [Physiological load and increased breathing resistance caused by filter respirators]. Arbete och hälsa (1974) 5. (Summary in English)

Received for publication: 1975-07-16 